\title{
LA GOBERNABILIDAD LOCAL EN EL CONTEXTO DE LA NUEVA GESTIÓN PÚBLICA: REQUISITO PARA LA GESTIÓN AMBIENTAL URBANA
}

\author{
Diana María Vásquez Avellaneda ${ }^{1}$ \\ Marcela Navarrete Peñuela ${ }^{2}$
}

Recibido el 31 de mayo de 2013 y aprobado el 17 de marzo de 2014, actualizado el 6 junio de 2014

\section{RESUMEN}

El análisis que se plantea en este artículo permite entender la complejidad que representa la significación y categorización de la Nueva Gestión Pública conforme a las bases teóricas que le sustentan, y es el punto de partida para analizar la Gestión Ambiental Urbana y la Gobernabilidad Local y vislumbrar así los niveles de similitud o divergencia existentes entre distintas realidades que presentan los Estados en atención a su nivel de desarrollo y contextos particulares.

\section{PALABRAS CLAVE}

Gestión ambiental urbana, gobernabilidad local, nueva gestión pública, control social.

\section{LOCAL GOVERNANCE IN THE CONTEXT OF THE NEW PUBLIC MANAGEMENT: REQUIREMENT FOR URBAN ENVIRONMENTAL MANAGEMENT}

\begin{abstract}
The analysis proposed in this article allows the understanding of the complexity, meaning and categorization the New Public Management represents in accordance with the theoretical bases that support it and is the starting point to discuss Urban Environmental Management and Local Governance and discern the levels of similarity or divergence between different realities that the States present in attention to their level of development and particular contexts.
\end{abstract}

\section{KEY WORDS}

Urban environmental management, local governance, new public management, social control.

\section{INTRODUCCIÓN}

Para el grupo de investigación AGESAT de la Universidad del Valle, la Gestión Ambiental Urbana se convierte en un tema central que debe orientar el proceso de investigación interdisciplinar y transdisciplinar. Congruente con este interés, se 
propuso desarrollar la investigación: "Estructuración del Observatorio de Conflictos Ambientales Urbanos", con el fin de generar un espacio académico político que permita el empoderamiento de la comunidad para el adecuado ejercicio de la participación y el control social.

El presente artículo es el resultado del trabajo exploratorio conceptual de la primera fase de este proyecto; en él, se plantea como objetivo lograr una aproximación al desarrollo teórico de la Gestión Ambiental Urbana y la Gobernabilidad Local en el contexto de la Nueva Gestión Pública. Para el logro de este objetivo fue necesario, en términos metodológicos, recurrir a una visión crítica que involucra diversos componentes -histórico, social, económico, cultural- para entender lo que significó en su momento y lo que en la actualidad representa la Gestión Ambiental Urbana frente a lo que se ha denominado la Nueva Gestión Pública. Para el logro del objetivo planteado en este artículo se hizo necesario examinar el desarrollo de estos conceptos desde un análisis descriptivo-analítico.

\section{DESARROLLO CONCEPTUAL}

\section{Políticas públicas y gestión ambiental}

Según Manteiga (2000, P. 76): "El desarrollo de la política ambiental implica un largo proceso de toma de decisiones. Parte de una preocupación ambiental y acaba en la adopción de medidas encaminadas a paliar tendencias desfavorables". La preocupación ambiental a la que hace referencia Manteiga tiene su origen en la afectación de la comunidad por un problema o interacción de problemas tipificados como ambientales, y es precisamente esa afectación la que motiva a la comunidad a buscar y formar parte de las soluciones. Es claro entonces que el proceso resolutorio de la problemática ambiental no está únicamente en manos del gobierno local, sino que demanda la participación activa de la comunidad.

En este escenario, la gestión ambiental urbana se convierte en el camino más viable y directo para la participación de los diferentes actores en procesos de control social, ordenamiento territorial y planificación y toma de decisiones, entre otros, gracias a los mecanismos establecidos por el marco institucional de la gestión ambiental. Según el BID (2007): "Estos mecanismos ayudan al desarrollo de un marco de gobernabilidad transparente y equitativo para la gestión ambiental y en consecuencia, un marco de gobernabilidad adecuado puede facilitar el camino hacia el desarrollo urbano sostenible", entendida la gobernabilidad como "[...] el modo en que una sociedad se organiza para tomar e implementar decisiones logrando un entendimiento, acuerdo y acción mutuos" (PNUD, 2000, p. 1).

La apertura de espacios para la participación e interacción entre el gobierno local y la sociedad civil para abordar adecuadamente 
la compleja y dinámica problemática ambiental urbana, dependerá en gran medida de "[...] la voluntad política de modificar la forma de intervención pública y la propia organización administrativa, en la línea estratégica, directora, evaluadora y cooperativa [...]" (URB-AL, 2001, p. 77). Lo anterior plantea para la administración pública un ineludible reto: responder a las nuevas tendencias del management público en el marco de la gobernabilidad y el control social.

\section{Gobernabilidad}

La conceptualización de la gobernabilidad ha sido el resultado de diferentes perspectivas teóricas, correspondientes a diferentes momentos históricos; este contexto dinámico se ha traducido en la dificultad para la formulación de una única definición de gobernabilidad. Así lo confirma Santos Zabala en el XIII Congreso Internacional del CLAD sobre la Reforma del Estado y de la Administración Pública, cuando afirma:

[...] el concepto de gobernabilidad ha tenido diversos significados, situación derivada de la complejidad y amplitud de los sujetos de estudio que aborda, así como a la variedad de escuelas y teorías que la han conceptualizado; por ello, gobernabilidad es un concepto ambiguo, difuso y difícil de operacionalizar en variables analíticas. (Santos, 2008, p. 1)

Sin embargo, para efectos de este trabajo las autoras acogen la definición presentada por el Programa GovernAsia, financiado por la Agencia Española de Cooperación Internacional para el Desarrollo (AECID):

La gobernabilidad es, [...] el atributo de los sistemas sociopolíticos (y por extensión económicos) caracterizados por su capacidad de formular e implementar decisiones públicas, es decir, de transformar las demandas o preferencias ciudadanas en políticas concretas. Así, se puede hablar de gobernabilidad cuando sus actores se interrelacionan para tomar decisiones colectivas y resolver sus conflictos y divergencias dentro de un marco institucional determinado (el sistema de gobernanza) dentro del cual formulan sus expectativas y estrategias. (GovernAsia, 2008, párr. 3)

\section{La gobernabilidad en el contexto de la globalización}

Según Joan Prats, director del Institut Internacional de Governabilitat de Catalunya (IIG), "La globalización está produciendo un nuevo orden de roles, asociaciones, partenariados entre los gobiernos, los ciudadanos y las empresas" (Prats, 2005, p. 25), a lo largo del eje Local-Global, lo que facilita -en teoría- la acción de la gobernabilidad a nivel local. Esto se confirma si tenemos en cuenta que la 
globalización, como promotora de la modernización del Estado, busca mayor transparencia en la administración pública y por ende, en la solución de los conflictos sociales, económicos y políticos de los Estados, lo cual, ayuda a consolidar la estructura de la gobernabilidad.

Pese a lo expuesto por el IIG, diversos autores sostienen que la globalización ha lesionado profundamente la gobernabilidad al debilitar significativamente dos de sus pilares: la democracia y la participación.

Al respecto, Pierre Calame, investigador del Institut de recherche et débat sur la gouvernance, sostiene:

En un contexto de mundialización, de crecimiento de las interdependencias donde la democracia y la escena política siguen organizándose casi exclusivamente a escala nacional, la crisis de la democracia es profunda en el momento en que, ideológicamente, ésta se convirtió en la referencia universal obligada (Calame, 2006, Recuperado de http://www.institut-

gouvernance.org/en/analyse/fiche-analyse319.html).

Esta crisis de la democracia a la que hace referencia el autor se acentúa si se tiene en cuenta que la igualdad política es la clave de la democracia, por tanto, "[...] a mayor desigualdad en la distribución de la riqueza, la información, las armas y otros recursos políticos, mayor tensión entre la democracia y la gobernabilidad. De hecho, en estos casos la exigencia de gobernabilidad acabará debilitando 0 deteriorando las instituciones formales democráticas" (Prats, 2001, p. 118), a la vez que la vulneración de la democracia impedirá garantizar los derechos sociales y políticos que brindan seguridad jurídica y social a los actores sociales y económicos, como lo asegura Concepción (2005).

Vargas (2005b), sostiene que la globalización ha limitado las oportunidades de desarrollo de las economías más frágiles, debilitado y socavado las bases del poder de los Estados nacionales, aumentando las tensiones sociales y por tanto la ingobernabilidad de las sociedades.

Asimismo, Concepción (2005) afirma que la globalización ha tenido serios efectos sobre la gobernabilidad al dejar la tarea de la cohesión social a los Estados nacionales y al mismo tiempo erosionar la capacidad de acción de estos estados, afectando severamente la democracia y la soberanía, sustento de la gobernabilidad, la igualdad social y la participación de la comunidad en la toma de decisiones; por tanto, es necesario que el ordenamiento internacional sea respetuoso de la diversidad de los países dentro de los límites de la interdependencia. 
En palabras del propio Joseph Stiglitz, dentro de los efectos negativos de la globalización se encuentran la amenaza a la identidad, a los valores culturales (elementos fundamentales para el logro de la participación en la gestión ambiental local, principalmente) y a la democracia:

La globalización, tal como ha sido defendida, a menudo parece sustituir las antiguas dictaduras de las elites nacionales por las nuevas dictaduras de las finanzas internacionales. A los países de hecho se les avisa que si no respetan determinadas condiciones, los mercados de capitales o el FMI se negarán a prestarles dinero. (Stiglitz, 2002, p. 308)

No existe duda de que medidas como las enunciadas anteriormente, atentan y restringen directamente la soberanía de los Estados limitándolos en sus acciones y decisiones sobre temas tan coyunturales como la inversión social. Estas medidas son constantes y de "severo cumplimiento" cuando se trata de países en desarrollo.

Desde el esquema impuesto por la globalización, Vargas (2005b, p.12), asegura que la gobernabilidad "[...] se logra mediante el desarrollo económico y social de los pueblos. De hecho, las sociedades local y regional son actores sociales para la promoción de un desarrollo más justo y equitativo", y concluye: "El desafío para una mejor gobernabilidad en un marco globalizador se centra en un sistema que logre el desarrollo integral del ser humano mediante la armonización de las metas macroeconómicas de crecimiento y de igualdad social" (Vargas, 2005b, p. 12).

\section{Gobernabilidad local}

Los desafíos para los gobiernos locales son cada día mayores dado que tienen que gestionar y velar por la inversión eficiente de los fondos, complacer las exigencias crecientes de la sociedad en lo relacionado con la democratización y socialización de la política y velar por el equilibrio ecológico, social, y económico de la ciudad y del entorno del que depende.

En la instalación de la Reunión de Ciudades y Gobiernos Locales Unidos (CGLU), Edgardo Bilsky ${ }^{3}$, al referirse a los actuales gobiernos locales, manifiesta que las crecientes responsabilidades de los gobiernos locales son cada día más importantes y diversas ya que deben brindar un servicio público cercano a la gente, son los garantes locales del respeto a la igualdad de los derechos ciudadanos y representan el interés general de la población en una ciudad o municipio. Además, se han convertido en uno de los principales actores del desarrollo económico y social. Por lo tanto, deberían poder garantizar la coherencia del desarrollo urbano a partir de la gestión global de sus territorios, es decir, tomando en cuenta diversos factores como equipamiento, servicios, ordenamiento equilibrado de barrios, acción social, lucha contra la pobreza, exclusión, etc. 
Vargas (2005a, p. 93-94), en su artículo "Hacia un nuevo diseño de gobernabilidad glocal postnacional", asegura que "tanto una mayor participación ciudadana como una mayor autonomía de los gobiernos locales son elementos imprescindibles para consolidar la gobernabilidad democrática"4, la cual se fortalece con el ejercicio autónomo de la autoridad para la formulación e implantación de sus propias políticas públicas como respuesta a las demandas de la ciudadanía.

Santos Zavala (2008), contempla la gobernabilidad en el nivel subnacional, como un resultado del proceso de reforma del Estado. El autor, refiriéndose principalmente a América Latina, resalta la participación de la comunidad en la formulación de políticas públicas:

[...] la nueva gobernabilidad local ha impulsado al mercado y a las redes de política pública como formas de organización del gobierno local, generándose con ello un nuevo proceso de formulación de políticas públicas, sustentado en la participación ciudadana y caracterizado por la existencia de múltiples lógicas de acción [...]. (Santos, 2008, p. 9)

Con respecto a la relación globalización-gobernabilidad local, desde la perspectiva latinoamericana, Ricardo García sostiene que la globalización se convierte en un inconveniente más para los gobiernos locales ya que es justamente "[...] en el ámbito local donde el proceso de desarrollo económico cobra vida, lo global y lo local se oponen precisamente en la percepción que hacen los ciudadanos del desarrollo" (García, 2002. Recuperado de

http://www.eumed.net/cursecon/ecolat/mx/RGJ022002A.htm)

El retorno a la democracia vivido por la mayoría de los países de América Latina, ha representado para el gobierno municipal la consolidación y fortalecimiento del poder local a través del proceso de descentralización que entrega autonomía a los municipios para realizar un gobierno más cercano a la sociedad y sobre todo con la posibilidad de incidir directamente sobre las prioridades y necesidades de la comunidad, y para la sociedad civil, la democracia representa la opción de intervenir en las decisiones que la afectan y el derecho a ejercer el control y vigilancia sobre la gestión de sus gobernantes y el cumplimiento de las funciones para las cuales fueron elegidos.

En síntesis, la gobernabilidad local debe ser entendida hoy, según el IIG, esencialmente como gobernabilidad urbana, esto implica la necesidad de generar las capacidades necesarias para formular estrategias y agendas compartidas de ciudad o ciudadregión y de aplicarlas en entornos dinámicos y cambiantes como lo son, los centros urbanos (Prats, 2005). 


\section{El Buen Gobierno}

El Banco Mundial (2003), en su página oficial, bajo el título "What is governance?" presenta varias definiciones de "good governance", correspondientes a diferentes instituciones internacionales:

UNDP: It is "... among other things participatory, transparent and accountable. It is also effective and equitable. And it promotes the rule of law".

OCDE: It " $\ldots$ encompasses the role of public authorities in establishing the environment in which economic operators function and in determining the distribution of benefits as well as the relationship between the ruler and the ruled (www.oecd.org)".

World Bank: It is:

[...] epitomized by predictable, open and enlightened policy making; a bureaucracy imbued with a professional ethos; an executive arm of government accountable for its actions; and a strong civil society participating in public affairs; and all behaving under the rule of law (World Bank, 1994). (Banco Mundial, 2013)

El término original "good governance" surge de las instituciones internacionales (FMI y BM, principalmente), como una "iniciativa" encaminada al control de la corrupción administrativa en los gobiernos de sus países miembros, mediante el seguimiento y la vigilancia de la forma en que se ejerce el poder en lo que respecta a la administración de los recursos económicos y sociales de un país para fines del desarrollo.

Pese a las "buenas intenciones" de la good governance promovida por el FMI y el BM, son numerosos los sectores y los gobiernos que guardan dudas al respecto, no solo sobre el concepto mismo sino también sobre las implicaciones de su aplicación, incluso hay autores como Saldomando (2002, p. 2) quien afirma:

Los multilaterales (BM. FMI. OCDE) en la primera generación de políticas de gobernabilidad consideraron que el buen gobierno y la buena gobernabilidad, era aquel que lograba hacer pasar las reformas económicas liberales surgidas del consenso de Washington, en condiciones de estabilidad política. Los gobiernos eran premiados según su habilidad política y según la autoridad ejercida para mantener el ritmo de las reformas ni retroceder o ceder ante consideraciones como costo social, protesta u oposición. 
En esta misma vía, Herrera opina que la "buena gobernanza" va en contravía de lo que sería el buen gobierno ya que:

[...] lo que se pretende no es el aumento de la participación democrática de los individuos y de los pueblos en el proceso de decisiones, ni el respeto de su derecho al desarrollo, sino obligar a los Estados nacionales a desregularizar los mercados, es decir, a regularlos únicamente por las fuerzas del capital mundial dominante. (Herrera, 2005, p. 290)

El autor sustenta, con suficiente fuerza argumentativa, su "desconfianza" en la ambigüedad conceptual que manejan las ya mencionadas instituciones internacionales alrededor del término "good governance" (Herrera, 2005).

El mismo autor sostiene, además: "Las condiciones de la buena gobernanza serán buscadas en vano mientras no se supriman los obstáculos estructurales que impiden a la gran mayoría de los países del mundo ejercer su derecho al desarrollo y a la democracia" (Herrera, 2005, p. 293). Para Herrera, está claro que es necesario cambiar el actual modelo de desarrollo, solucionar el problema de la deuda externa, y controlar estrictamente las actividades de las transnacionales, origen de intercambios irregulares:

La insistencia del FMI en hablar de buena gobernanza, convertida en una de las palancas de la condicionalidad de la ayuda a los países del Sur y de los acuerdos de reducción de su deuda externa, pone en evidencia la politización creciente de sus intervenciones y la deriva de sus misiones más allá de lo que define su mandato. (Herrera, 2005, p. 292)

En la necesidad de encontrar una definición de "buen gobierno" más "acorde" a las realidades de los países en desarrollo, las autoras de esta investigación han acogido para este trabajo, la definición propuesta por el Sistema Económico Latinoamericano (SELA) en la Reunión de Consulta Regional sobre la Reforma de los Bancos Multilaterales de Desarrollo, celebrada en Washington D.C, el 21 de abril de 1996:

[...] "buen gobierno" se refiere específicamente a la dimensión económica y social de la gestión pública, en la cual se le atribuye al Estado una responsabilidad clave en la conducción general de la economía y en el desarrollo integral, sustentable y equitativo de la sociedad. En el mismo orden de ideas, se reconoce también que el sector público debe ser eficiente en sus políticas económicas y sociales, no sólo debido a su responsabilidad en la consolidación de la estabilidad democrática, sino también porque necesita legitimarse como interlocutor válido en 
materia de acceso a los recursos multilaterales, sin que ello signifique introducir condicionalidades de tipo político. (SELA, 1996, p. 5)

El "deber ser" del buen gobierno puede ser entendido a partir del planteamiento de Vargas (2005a), para quien el buen gobierno, esencia de la gobernabilidad democrática, se centra en los "[...] procesos de formulación y ejecución de políticas públicas creadoras y reguladoras de instituciones y mecanismos que permitan a los actores colectivos, acordar, negociar y asumir funciones de vigilancia de la esfera pública." (p. 94). Según este autor, la nueva gestión pública "[...] requiere que los procesos de formulación e implementación de las políticas públicas estén estrechamente vinculados a las capacidades del Estado [...]" ( $p$. 94).

\section{¿Cómo medir el buen gobierno?}

Medir el "buen gobierno" resulta un reto para la sociedad y para el mismo sector administrativo. Los diferentes organismos internacionales impulsores de la "buena gobernanza" han propuesto diversas baterías de indicadores para medir lo que, a su juicio, consideran que es la "eficiente acción administrativa de los gobiernos". La más reciente propuesta del BM está plasmada en "Governance Matters VIII" correspondiente al periodo 1996-2008, los indicadores agregados planteados se basan en 33 fuentes independientes de datos y en cientos de variables para captar, mediante encuestas, la opinión sobre la gestión de gobierno de miles de hogares, empresa, organizaciones no gubernamentales y expertos en sector público (Banco Mundial, 2009).

Las seis "dimensiones esenciales" en las que se agrupan estos indicadores son: voz y rendición de cuentas, estabilidad política y ausencia de casos graves de violencia, efectividad gubernamental, calidad regulatoria, Estado de derecho y control de la corrupción. Estos indicadores son los mismos que subyacen a los "principios de la buena gobernanza" adoptados por la Unión Europea y plasmados en el Libro Blanco sobre la Gobernanza Europea.

Frente a los indicadores utilizados por el BM para medir el buen gobierno, son muchos los autores que discrepan de ellos debido a que, a juicio de los expertos, dichos indicadores presentan serios problemas de forma y de fondo en su construcción. Corroborando lo anterior, Aart Kraay, economista principal en el Grupo de Investigaciones del Banco Mundial, afirma que la medición de la gobernabilidad plantea dificultades, y no se tiene la certeza de que la información suministrada por los indicadores sea totalmente exacta (Banco Mundial, 2006).

Por otro lado, Saldomando (2002, p. 5), se cuestiona sobre qué es lo que se está midiendo en gobernabilidad y sostiene: "Dado el hecho de que no existe consenso ni referencias empíricas establecidas sobre la gobernabilidad democrática y su 
monitoreo, los sentidos que se le den al concepto de 'gobernabilidad eficaz o ineficaz' son claves". Otra observación realizada por Saldomando, hace referencia a que esta "caja de herramientas" universalizante, propuesta por el BM, deja por fuera del análisis elementos tan importantes como: los contextos locales, los modos de regulación y la elección de las variables del enfoque adoptado.

Como si respondiera al interrogante planteado por Saldomando, el PNUD (2000, p. 1) en Indicadores de gobernabilidad: Guía del usuario, sostiene que "los indicadores de gobernabilidad pueden utilizarse para hacerle seguimiento y evaluación a los programas y proyectos de gobernabilidad así como para establecer puntos de referencia, objetivos y metas desde la perspectiva del desarrollo".

Es de anotar que los indicadores de gobernabilidad propuestos por el PNUD también han sido objeto de críticas. Girvan (s.f.), identifica tres tipos de problemas en estos indicadores: sesgo cultural y político $^{5}$, fuentes de información del PNUD y construcción de los indicadores numéricos (las puntuaciones máxima y mínima varían enormemente para los diferentes indicadores).

Otra alternativa para "medir" el buen gobierno es a través del cumplimiento, por parte de los gobiernos, de las "siete normas de gobernanza urbana" propuestas por el Programa de las Naciones Unidas para los Asentamientos Humanos: equidad, seguridad, eficiencia, sustentabilidad, descentralización, transparencia y gestión responsable (una gestión urbana transparente y abierta, y una ciudadanía vigilante de sus derechos) y compromiso cívico y ciudadano (ciudades que aseguren la participación activa de la ciudadanía en la toma de decisiones, son más gobernables).

Sin embargo, los mejores indicadores del "buen gobierno" son el nivel de gobernabilidad y la capacidad de gestión y de ejecución del programa de gobierno por parte de la administración local, así como el grado de satisfacción y el nivel de confianza de la sociedad (percepción social) en sus gobernantes y en las instituciones (Fleury, 2002). En este punto, tanto la formulación de los indicadores de gestión de políticas, como su validación con los distintos actores presentes en la ciudad, serán de gran utilidad ya que permitirán a la comunidad saber cuánto han cumplido sus gobernantes de lo propuesto en los diferentes planes de gobierno y a los administradores locales conocer las fortalezas y debilidades de su gobierno, así como la opinión que tienen los ciudadanos de su gestión, además permitirán inferir si la ciudad marcha por el camino indicado para el logro de la sostenibilidad. 


\section{BASES CONCEPTUALES DE LA NUEVA GESTIÓN PÚBLICA (NGP)}

La gestión pública, debe ser entendida, según Metcalfe (1999), como gestión a nivel "macro", contraria a la gestión privada o "micro". Según Prats (2001, p. 109):

La gestión pública se refiere al cambio, no a nivel organizacional o micro [...], sino a nivel macro o estructural entendido como orientando la transición hacia un nuevo marco institucional [...] cambiar las reglas del juego (la "governance" o la estructura institucional) es un cambio de naturaleza diferente al que implica cambiar las estrategias de los actores individuales.

\section{Antecedentes}

La gestión pública, inicialmente conocida como management público, tiene sus orígenes teóricos en el Reino Unido, sus desarrollos metodológicos en el mundo anglosajón y su "campo de experimentación" en todo el planeta. No obstante, algunos administrativos franceses "reclaman como originalmente galo el término management" (Guerrero, 2001).

La gestión pública o management público, se presentó, durante la década de los 70, como un:

[...] conjunto de doctrinas de aplicación general y universal caracterizado por rasgos de portabilidad y difusión, así como de neutralidad política. Esto significó por una parte, que sus principios y técnicas se presentaran como una respuesta válida para los problemas de la gestión pública en multitud de países. (Jarquín y Losada, 1999, p. 16)

En los años 80, con la mundialización de la economía y demás efectos de la globalización, la naturaleza y especificidad de muchos de los problemas públicos cambia, lo que "pondría de manifiesto la imposibilidad de encontrar soluciones prét-á-porter en el sector privado. Como consecuencia, las organizaciones públicas deberían o bien adaptar sustancialmente las técnicas privadas o bien construir sus propios modelos" (Jarquín y Losada, 1999, p. 16). El marcado interés del sector público por las técnicas del management:

[...] refleja las dificultades que encuentra la administración pública para adaptarse a la escala y complejidad de los problemas que le plantea la sociedad actual. Las nuevas circunstancias económicas, políticas y sociales ponen de manifiesto las limitaciones de las perspectivas tradicionales que han 
proporcionado a la administración sus modelos de conducta. (Jarquín y Losada, 1999, p. 16)

Es así como, en la década de los 90, la gestión pública buscó elaborar nuevos conceptos y modelos de gobierno que modificaran los procesos de formulación de políticas, renovaran los criterios utilizados para juzgar la eficacia de las políticas y transformaran los patrones y procesos de responsabilidad pública (Metcalfe, 1999), lo que devino en la creación de la denominada Nueva Gestión Pública. Respecto a la gestión pública en los años 90, Les Metcalfe, escribe en su artículo "La gestión pública: de la imitación a la innovación":

Los valores básicos en torno a los cuales giró la reforma durante los años noventa se resumen en lo que ha venido a conocerse como "las tres E" economía, eficiencia, eficacia-, entendidas éstas como la erradicación del despilfarro, la racionalización de los servicios y la especificación de objetivos que orienten los recursos directamente hacia la resolución de los problemas. Desde ese punto de vista, la imitación de los métodos empresariales parece la respuesta más racional. En los años noventa, debido al ritmo del cambio y a la complejidad de las tareas que debe afrontar el Estado, la "triple E" no constituye ya una base suficiente para la reforma. Supone más bien un grado de estabilidad constitucional e institucional que no se puede dar por descontado. (Metcalfe, 1999, p. 49)

Según García (2007), la NGP surge por la pérdida de credibilidad del sector público como gestor del bienestar ciudadano, lo que obligó a las instituciones públicas a actuar aplicando los principios de economía, eficiencia y eficacia:

Estas nuevas demandas, cada vez más importantes como consecuencia de la magnitud del déficit público en prácticamente la totalidad de países, tuvieron en un primer momento un importante impacto en los procesos de construcción de políticas públicas, pero en la actualidad no se circunscriben únicamente a la esfera política o ministerial, sino que se han ampliado a todas las actuaciones de la administración en sus diferentes órdenes territoriales. Así, las administraciones estatales, autonómicas, provinciales y locales se ven envueltas en procesos de regeneración, de cambio. Nuevos patrones de actuación y comportamiento, comunes internacionalmente, son los que han llevado a diseñar un nuevo sistema operativo público, una nueva filosofía de actuación: la nueva gestión pública. (García, 2007, p. 38) 
La nueva gestión pública o new public management es, pues, el resultado de la modernización del Estado, es decir, es la transformación de una gestión pública caracterizada por la ineficacia, la ineficiencia y la corrupción, a una gestión que busca, como la empresa privada, obtener los mejores resultados al menor coste posible (economía, eficiencia, eficacia y transparencia), a través de diversos procesos de reforma del Estado, que buscan, además, la satisfacción del cliente. Según Jarquín y Losada (1999), la NGP, ha permitido pasar de una inversión centrada en la creación de infraestructura física y en la transferencia de tecnología, a "invertir en capital humano, de aplicar políticas macroeconómicas sanas como conditio sine qua non, y de crear el entorno propicio para que los diversos mercados (financieros, laborales, etc.) funcionen adecuadamente, es decir, de manera competitiva" (Jarquín y Losada, 1999, p. 1).

La NGP establece una estrecha relación con la gobernabilidad a través de los principios de transparencia, participación y descentralización en los diversos niveles de gobierno:

La nueva gestión pública incluye procesos de descentralización y de evolución en todos los niveles de gobierno, aunque en su implantación no siempre consideró las complejidades locales. Homogeneidad y rigidez de normas son obstáculos para la autonomía de los procesos de descentralización y afectan el avance en función de sus propias posibilidades, oportunidades y potencialidades, definiendo sus propias instancias y mecanismos de participación, los cuales, a su vez, se orientan a la gestión de proyectos y construcción de obras sin otorgar a los ciudadanos el poder de decisión para convertirlos en actores políticos. Mayor participación ciudadana y autonomía de los gobiernos locales son elementos imprescindibles para consolidar la gobernabilidad democrática ${ }^{6}$. (Vargas, 2005, p. 21)

\section{Definiciones}

Son numerosas las definiciones que se encuentran disponibles en la literatura. No obstante, la mayoría de los autores coinciden en identificar, como elementos estructurantes de la NGP, la economía, la eficiencia y la eficacia.

Echebarría y Mendoza (1999, p. 33-34), definen la NGP como:

[...] un movimiento de nuevas ideas que se concentra en el mejoramiento del desempeño mediante el traslado del énfasis desde el control de los insumos hacia el control de los productos permitiendo así una mayor discreción gerencial, y en la promoción de una mayor transparencia y responsabilidad. 
Según Pollitt y Bouckaert (2000, citados por López, 2003, p. 9), es aquella gestión que:

[...] conduce a un gobierno más económico y eficiente, con servicios de mayor calidad y programas más eficaces, y además, simultáneamente, introduce cambios como la ampliación del control político, mayor libertad a los gerentes para que lleven a cabo su gestión, mayor transparencia gubernamental y una mejora de la imagen de aquellos ministros y líderes más comprometidos.

Para García (2007, p. 44), la NGP es aquella que:

[...] persigue la creación de una administración eficiente y eficaz, es decir, una administración que satisfaga las necesidades reales de los ciudadanos al menor coste posible, favoreciendo para ello la introducción de mecanismos de competencia que permitan la elección de los usuarios y a su vez promuevan el desarrollo de servicios de mayor calidad. Todo ello rodeado de sistemas de control que otorguen una plena transparencia de los procesos, planes y resultados, para que por un lado, perfeccionen el sistema de elección, y, por otro, favorezcan la participación ciudadana.

Es importante aclarar que instituciones internacionales como el $\mathrm{BM}$, el FMI y la OCDE, utilizan el término Reforma Estructural para referirse a la NGP, es por esto que Guerrero (2001), define la nueva gestión pública como:

[..] un movimiento de reforma del sector público, basado en el mercado como modelo de relación política y administrativa, cuyo sustento doctrinario está fundamentado en la opción pública, la teoría del agente principal, la gerencia de calidad total y la economía de costos de transacción.

El mismo autor se refiere a la NGP así:

El neomanejo público todavía es un modelo de implementación uni-lingüe y uni-cultural, un fenómeno inherente a un puñado de países anglosajones que se exporta como una mercancía para que se consuma en los países subdesarrollados a través de las ofertas que se concentran y luego se distribuyen a través de la OCDE. Esta exportación mercantil es asegurada por medio del financiamiento condicionado del Banco Mundial y el Fondo Monetario Internacional, que se conoce con el eufemismo de "reforma estructural". (Guerrero, 2000) 
En síntesis, puede definirse la NGP como un enfoque de compresión, análisis y tratamiento de los problemas propios de la Administración Pública a través del uso de las estrategias propuestas por el management para el logro de mayor eficiencia, eficacia y efectividad en el ejercicio de la función pública. Asimismo, puede decirse que el principal objetivo de la reforma del Estado impulsada a través de la NGP es cambiar la administración pública y la cultura administrativa centrando los esfuerzos en "los resultados organizacionales, la gestión individual y los incentivos del mercado (incluyendo, cuando sea posible, la privatización)" (López, 2003, p. 10).

\section{Fundamentación teórica}

El paradigma post-burocrático se debe a Michael Barzelay, en tanto que el concepto de gobierno empresarial es obra de David Osborne y Ted Gaebler. El nuevo manejo público o nueva gestión pública es el más representativo de la globalización y consiste en un prototipo de estandarización administrativa (Guerrero, 2001).

Echebarría y Mendoza (1999), aseguran que el sustento teórico que subyace a la mayoría de los cambios promovidos por la NGP está formado por un conjunto de valores, principios y técnicas que se enmarcan en las llamadas ciencias del management.

\section{Principios orientadores de la NGP}

Con el fin de entender los principios que orientan la acción de la NGP es conveniente conocer las motivaciones que dieron lugar a la "entusiasta" adopción, por parte de los Estados, de las llamadas Reformas de Primera Generación:

No es de extrañar que el movimiento de la reforma del sector público se haya difundido con tanto entusiasmo en el mundo. Gravita en torno a ella el supuesto -o creencia- de que su ejercicio "conduce a un gobierno más económico y eficiente, con servicios de mayor calidad y programas más eficaces, y además, simultáneamente, introduce cambios como la ampliación del control político, mayor libertad a los gerentes para que lleven a cabo su gestión, mayor transparencia gubernamental y una mejora de la imagen de aquellos ministros y líderes más comprometidos" (Pollitt y Bouckaert, 2000). (López, 2005, p. 9)

López asegura que realizadas las reformas de primera generación (privatización, desregulación, descentralización, etc.), los procesos de "modernización" de la gestión pública buscan:

Introducir nuevas lógicas en la forma de actuación de las instituciones gubernamentales, 
promoviendo la gestión por resultados, enfatizando un carácter más gerencial que procedimental, ubicando a los usuarios como centro de las preocupaciones de gestión y transparentando los actos públicos para mejorar los niveles de confianza de la ciudadanía sobre lo público. La puesta en marcha de estas iniciativas garantizaría una asignación y utilización de los recursos públicos bajo un estricto criterio que incorpora eficiencia, eficacia y calidad. (López, 2005, p. 11-12)

Según López (2005), el panorama anteriormente descrito permitió, en un ambiente pletórico de optimismo, formular los objetivos que justificarían la razón de ser de las reformas a la gestión pública:

- Mejorar la asignación y utilización de recursos públicos administrados por las instituciones del Estado (formulación de objetivos vs. mecanismos de control y evaluación).

- Mejorar la calidad de servicio y atención al usuario (identificación de usuarios y sus necesidades, definición de estándares de desempeño, generación de departamentos de quejas y reclamos, y creación de la figura del defensor de los derechos de los usuarios).

- Hacer más transparentes los actos gubernamentales a partir del perfeccionamiento de los mecanismos de control y evaluación de las instituciones públicas.

Además de los objetivos de la NGP es pertinente, para los propósitos de este apartado, mencionar las líneas características que, según Shepherd (1999, p. 78), vinculan la NGP con la gestión del sector privado: delegación de la toma de decisiones, orientación hacia el desempeño, orientación hacia el cliente y orientación de mercado.

Es en este contexto de reformas "hacia adentro" planteado por la NGP que fue realizada la propuesta de Osborne y Gaebler sobre Los cinco principios orientadores de la NGP, ampliamente conocidos como las "Cinco R": Reestructuración, Reingeniería, Reinvención, Reconceptualización y Realineación. Pese a las expectativas generadas por las ventajas que se obtendrían con la puesta en marcha de las Cinco R, estos cinco principios orientadores de la NGP han sido cuestionados por varios autores por considerarlos "abstractos", entre ellos la OCDE, esta organización:

[...] alerta sobre la posibilidad de considerar a los principios de la NGP como un modelo unívoco de reforma y transferible a cualquier país, sin tomar en cuenta los diferentes sistemas políticos y administrativos que, naturalmente, implicarán formas de operacionalización muy divergentes de estos criterios considerados como "bastante abstractos". (López, 2003, p. 12) 
La OCDE, también recomienda pensar en reformas más profundas, selectivas e incrementales, en las que se privilegie el enfoque "pragmático" sobre el "dogmático".

\section{Introducción de las técnicas del "management" privado en el sector público}

Los aportes de las ciencias de gestión (management) a la reforma del Estado no son nuevos, estos aportes han variado acompasados con la dinámica de la teoría del desarrollo. Esta aseveración es confirmada por Echebarría y Mendoza (1999, p. 17):

\begin{abstract}
El management -movimiento que ha ganado madurez y notoriedad en los Estados Unidos gracias al auge empresarial y al valor social que se atribuye a la racionalidad económica, los métodos científicos del trabajo y la responsabilidad individual- ha tenido, desde sus orígenes, un considerable eco en la administración pública estadounidense.
\end{abstract}

Desde la década de los 90 se ha suscitado una serie de cambios en la configuración de la administración pública que obedecen a las transformaciones del entorno, principalmente al fenómeno de la globalización. Las presiones del mercado (economía, eficiencia y eficacia), a las que busca responder el management en el sector privado, hoy son también exigencia de la administración pública.

Pese a la transferencia de variadas técnicas del management a la administración pública, los resultados no fueron los esperados. Según Metcalfe (1999), el problema radica principalmente en la ausencia de una conceptualización propia:

La gestión pública, después de haber tomado en préstamo numerosos elementos de la administración de empresas, carece de un fundamento teórico adecuado. No tiene lógica propia [...] Curiosamente, su dependencia de las soluciones orientadas al mercado ha desviado la atención de los reformadores de la gestión de los problemas de gobierno que la teoría de la elección social se había propuesto resolver inicialmente. (Metcalfe, 1999, p. 50)

En esta primera etapa, tanto el escepticismo frente al lenguaje propio de las ciencias de la gestión, como la mala interpretación que hizo el sector público del espíritu del management, generaron desconfianza y resistencia frente a su aplicación en la solución de problemas de la administración pública.

Dado que la administración pública es singular, dinámica y se enfrenta a nuevos y diferentes problemas a los que debe darles solución, sería de esperarse que la gestión pública pasara, como 
dice Metcalfe, de la simple imitación de las técnicas propias del management a la innovación en la NGP, generando procesos de aprendizaje institucional y valor público. Sin embargo, para poder pasar de la imitación a la innovación, la gestión pública necesita nuevos cimientos teóricos.

Por otro lado, la gestión pública se enfrenta a serias dificultades prácticas para incrementar las capacidades de aprendizaje en el plano interinstitucional ya que, como asegura Metcalfe (1999, p. 64): "los procesos políticos convencionales bloquean con frecuencia el aprendizaje, ya que la ideología se impone sobre la realidad o los intereses particulares se resisten a la evaluación y cambio de las políticas".

A pesar de los esfuerzos realizados hasta hoy por la NGP para adaptar las técnicas y teorías del management privado a las exigencias de la gestión pública, son varios los autores que como la OCDE cuestionan no solo "la 'versión restringida' del New Public Management, asentada sobre tres valores básicos (la trilogía economía, eficacia y eficiencia) y con énfasis en la gerencia de contratos, la introducción de mecanismos de mercado en el sector público y la vinculación del pago con el desempeño" (López, 2003, p. 12), sino también lo que Christensen y Laegreid (2007) denominan experiencias negativas (la delegación estructural, el desempeño directivo y las organizaciones especializadas) resultado de las reformas introducidas por la NGP.

\section{LA NGP Y SUS EFECTOS EN LA ADMINISTRACIÓN LOCAL}

La NGP no ha conocido restricciones para su aplicación en los diferentes niveles territoriales. Sin embargo las "buenas prácticas" reportadas en la bibliografía se relacionan principalmente con el nivel local; para Cabrero (2005), esta "rica cosecha" de la NGP en el espacio gubernamental local tiene una explicación lógica:

Evidentemente esto en parte es lógico dado que en los gobiernos locales es más probable que las reformas tengan en el corto o mediano plazo algunos resultados a observar, lo cual se debe a una cuestión de escala. Por otra parte se puede pensar que la fuerte orientación que los gobiernos locales tienen hacia la prestación de servicios públicos que son claramente identificables en sus modalidades de operación y en sus resultados, así como su vinculación directa con usuarios precisos, facilita la adopción de las herramientas de la NGP las cuales se caracterizan justamente por una preocupación por acotar el ámbito de acción de la reforma, por focalizar los efectos buscados, y por llevar a cabo una medición sistemática de resultados. (Cabrero, 2005, p. 3) 
Dado el rol que desempeña la administración pública en el nivel local, los principales efectos de su accionar se reflejarán en el grado de gobernabilidad y en las políticas públicas a través de las cuales intente dar solución a los problemas que afrontan los ciudadanos o clientes de la administración local.

Vargas (2001), explica que la gobernabilidad se toca estrechamente con la gestión pública en la medida en que los diferentes regímenes políticos tienen el reto de demostrar día a día su capacidad de gobernar y de ejercer un "buen gobierno" en un marco de legitimidad, como posibilitador de mejora de la calidad de vida de los ciudadanos.

El "buen gobierno" local y la NGP se retroalimentan en su práctica en la medida en que el "buen gobierno" demanda de la reforma del Estado la creación de espacios favorables para el buen desempeño económico y social, a la vez que enriquece su quehacer:

[...] incorporando, como prácticas regulares, rutinas gubernamentales y estilos de gestión que: privilegian la transmisión y recepción de información entre gobierno y ciudadanos; le permiten establecer una interacción permanente con las comunidades y sus organizaciones sociales; abren cauces para la participación y la concertación entre los agentes locales públicos y privados. (Brito, 2002, p. 262)

Según Brito, la NGP demanda del "buen gobierno" local la capacidad de articular las potencialidades sociales en su territorio con el fin de sostener el desarrollo socioeconómico, aprovechando los espacios que abren la democracia, la descentralización, el desarrollo tecnológico y las demandas de participación y de comunicación entre gobierno y sociedad, y capacidad de respuesta que en el caso de los gobiernos locales está asociada, entre otros aspectos, a la capacidad para formular y poner en funcionamiento políticas públicas que mejoren las actividades económicas y sociales y, por ende, el desarrollo local.

En cuanto a los efectos sobre las políticas públicas, es claro que, independientemente de su intencionalidad, estas no podrán cumplir con los objetivos propuestos y sus resultados no serán los esperados ni los deseados si no se generan las condiciones propicias para una adecuada formulación, implementación, evaluación y posterior reformulación de dichas políticas.

Vargas (2005b), sostiene al respecto que el nuevo modelo de gestión gubernamental demanda una estrecha relación y coordinación entre los procesos de formulación y establecimiento de las políticas públicas y las capacidades del Estado y sus contribuciones al logro de la gobernabilidad democrática. Según este autor: "La nueva gestión pública es un proceso de reingeniería y rediseño de las relaciones entre los actores involucrados en la esfera estatal para la creación de valor público 
mediante el fortalecimiento de las instituciones a partir del aumento del capital social y el aprendizaje organizacional, lo cual promueve espacios de confianza entre el sector público y la ciudadanía" (Vargas, 2005b, p. 22), lo que, indiscutiblemente, redundaría en el fortalecimiento de la gobernabilidad local y en la consolidación de la NGP como estrategia de cambio local.

A nivel urbano, la NGP, cuyo objetivo apunta al logro de una gestión local de calidad y al mejoramiento de la productividad de las ciudades, "amplía y revaloriza" al municipio como actor político, aumenta los niveles de gobernabilidad y la capacidad de gobierno vía participación ciudadana en la formulación e implementación de políticas para la construcción de ciudad, lo que implica "cambios muy profundos en la administración pública que hacen necesaria la aplicación de códigos de conducta ética [...] y el uso correcto y ético de los recursos públicos [...]" (Ferrer, 2005, p. 634) con el fin de mejorar la calidad de vida de los ciudadanos.

Lieberherr (2002), asegura que las ciudades sostenibles no deben serlo solo en el plano medioambiental: "Deben ser sostenibles social, económica, cultural, institucional y políticamente" (p. 1) y en este objetivo, la NGP juega un rol fundamental al liberar a la democracia del obstáculo de la "sobrecarga" de demandas que generan ingobernabilidad (Vargas, 2001).

Ahora bien, transcurridas casi tres décadas de puesta en escena la NGP en diversas regiones del planeta, incluida Iberoamérica, empiezan a hacerse evidentes en la administración pública local algunos efectos con los que -aparentemente- no se contaba; estos efectos están relacionados con las que Christensen y Laegreid (2007) llaman "experiencias negativas con las reformas promovidas por la NGP", entre las que sobresalen la delegación estructural, el desempeño directivo y las organizaciones especializadas, generadoras de pérdida de autoridad y responsabilidad, así como de profunda segmentación que se ve reflejada no solamente en la estructura misma de la administración pública, sino también en la formulación de políticas públicas a nivel local, lo que, en opinión de Cabrero (2005, p. 17), podría "[...] retardar o incluso interferir con procesos más amplios de consolidación de una nueva práctica democrática local".

Para terminar, es necesario clarificar el papel que, en el nivel local, debe jugar la administración pública si lo que se quiere es, como dice Borja (2000), "un proyecto político e intelectual para la ciudad". En este sentido, dice el autor, que las administraciones públicas y en especial el gobierno local:

[...] no pueden renunciar a un rol regulador $\mathrm{e}$ impulsor de la transformación y de la cohesión de los tejidos urbanos. Su rol no es ni imponer sin debate su imperio en aquellas funciones limitadas que posee en exclusiva ni seguir cerrilmente las dinámicas del mercado, ni 
tampoco condenarse a la no-decisión escuchando a unos y a otros sin tomar partido. (Borja, 2000, p. 80)

\section{Críticas a la NGP}

Autores como Echebarría, Mendoza, Metcalfe, Cabrero y Teelken, entre otros estudiosos del tema, plantean fuertes críticas a la NGP, coincidiendo en que la limitación fundamental de la NPG es "su pertenencia a una lógica de racionalidad económica individual y egoísta, concebida para ordenar el comportamiento de una organización independiente" (Echebarría y Mendoza, 1999, p. 41).

Pese a que autores como Barzelay, Osborne y Gaebler, Holmes y Shand y Aucoin han defendido férreamente la idea de que la NGP es un nuevo paradigma de cambio, hoy varios de ellos la consideran agotada:

En la actualidad, las críticas a la NGP van en ascenso en muchos países. Recientemente, Osborne (2006) afirma que la era de la NGP ha sido relativamente breve y "transitoria" entre la tradición burocrática de la administración pública (AP) y la tradición pluralista de la nueva gobernanza pública (GP). (Suk, 2007, p. 512)

Otros autores prefieren centrar la crítica a la NGP en su enfoque intragubernamental, puesto que acentúa la eficiencia económica de programas y unidades administrativas a fin de reconstruir el equilibrio financiero de la hacienda pública y de este modo reconstruir la capacidad económica del gobierno, pero sin que el énfasis en la costo-eficiencia se haya traducido necesariamente en un gobierno cuyas políticas y programas generan beneficio público, generan valor, y respetan además los valores políticos de un Estado republicano y democrático. Se ha ganado en eficiencia, pero no en calidad de bienes y servicios públicos. La NGP fue pensada y ejecutada teniendo presente como objetivo primero la salud financiera del gobierno, suponiendo bastante alegremente que los objetivos que se realizan en modo eficiente tienen significación social y cambian las condiciones sociales negativas e indeseadas.

Algunos otros investigadores coinciden en la preocupación de que los valores tradicionales de la administración pública (democracia, equidad social y humanización) están amenazados por el empeño en alcanzar la eficiencia en la NGP (Teelken y van Gestel, 2004; Guerrero, 2009; Dussauge, 2009; Pliscoff, 2012).

Estos y otros problemas identificados en la NGP motivaron a los investigadores de las ciencias sociales a proponer una nueva reforma Post NGP con el fin de remediar en la administración las experiencias negativas dejadas por la NGP. 


\section{EL CONTROL SOCIAL Y LA NGP}

A finales de la década de los años 80 e inicios de los 90, la OCDE (1991) en su libro titulado La administración al servicio del público, resaltaba la importancia de fortalecer las relaciones entre las organizaciones públicas y los ciudadanos y proponía el tema como uno de los principales retos que debía afrontar la NGP.

El ejercicio del control social mediante la participación de la comunidad, permite a la administración pública, consolidar la democratización de las relaciones de poder en la gestión pública, disminuir las asimetrías en la representación y abrir espacios políticos al ciudadano para la formulación de políticas públicas (Cunill, 1999). Asimismo, permite a la administración pública conocer de manera directa tanto los problemas que aquejan a la comunidad como la percepción que los ciudadanos tienen de la gestión del gobierno local.

Conscientes de la importancia del control social en el seguimiento y evaluación de la gestión pública, los países iberoamericanos han firmado la denominada Carta Iberoamericana de Participación Ciudadana en la Gestión Pública (CLAD, 2009), en la cual, los gobiernos se comprometen a viabilizar y propiciar los mecanismos y espacios de participación de la ciudadanía en los procesos de control y evaluación.

\section{CONCLUSIONES}

Los innumerables problemas ambientales, especialmente los que devienen del ámbito urbano, requieren soluciones o respuestas que no solo dependen de la gestión del gobierno local, sino que demandan de la efectiva participación de la comunidad; quienes en últimas son los sujetos de la gestión ambiental urbana, encargados de ejercer control social y lograr incluso la materialización de la gobernabilidad. No obstante, una verdadera gestión ambiental urbana debe, igualmente, centrar su atención en el objeto propio de la gestión urbana: ciudades sostenibles.

Existen unos principios fundantes en la administración pública que deben prevaler: la democracia, la equidad social y la humanización; por tanto, son innegociables y deben perdurar en el tiempo. Bajo estos supuestos no es dable para la administración pública amenazar o poner en riesgo sus principios fundantes bajo el argumento del logro o consolidación de la eficiencia y economía que debe orientar a la administración. 


\section{REFERENCIAS}

- Banco Interamericano de Desarrollo. (2007). El Marco de la Gobernabilidad para la Gestión Ambiental Urbana. Recuperado de http://www.iadb.org/SDS/ENV/site_7025_s.htm

- Banco Mundial. (2006). Comunicado de prensa No: 2007/63/WBI. Recuperado de http://web.worldbank.org/WBSITE/EXTERNAL/BANCOMUNDI ALI NEWSSPANISH/0,,contentMDK:21053360 pagePK:64257043 pi PK:437376 theSitePK:1074568,00.html

- (2009). Governance Matters VIII. Aggregate and Individual Governance Indicators. Washington, D.C.

- (2013). What is governance? Recuperado de http://web.worldbank.org/WBSITE/EXTERNAL/COUNTRIES/ MENAEXT/EXTMNAREGTOPGOVERNANCE/0,,contentMDK :20513159 pagePK:34004173 piPK:34003707 theSitePK:497 024,00.html

- Bilsky, E. (2004). Ponencia presentada en la Reunión de Ciudades y Gobiernos Locales Unidos (CGLU), París, Francia, 5 mayo.

- Borja, J. (2000). Los Desafíos del Territorio y los Derechos de la Ciudadanía. Memorias Seminario Internacional "Costos y Financiamiento de la Capitalidad", México.

- Brito, M. (2002). Buen gobierno local y calidad de la democracia. Revista Instituciones y Desarrollo, 12-13, 249-275.

- Cabrero, E. (2005). La nueva gerencia pública y los procesos de reforma gubernamental en municipios de América Latina: ¿avance o retroceso para una gobernanza democrática? Ponencia presentada en el $X$ Congreso Internacional del CLAD sobre la Reforma del Estado y de la Administración Pública, Santiago de Chile, Chile, 18-21 octubre.

- Calame, P. (2006). El desfase de la gobernanza actual. Tesis para repensar la gobernanza. Recuperado de http://www.institut-gouvernance.org/en/analyse/ficheanalyse-319.html

- Christensen, T y Laegreid, P. (2007). Reformas post nueva gestión pública. Tendencias empíricas y retos académicos. Revista: Gestión y Política Pública. Vol. XVI. Nº02. Segundo semestre. Centro de Investigación y Docencia Económicas. México D.F.

- CLAD -Centro Latinoamericano de Administración para el Desarrollo-. (2009). Carta Iberoamericana de Participación Ciudadana en la Gestión Pública. Recuperado de http://www.clad.org/documentos/declaraciones/cartaiberoamericana-de -participacion-ciudadana

- Concepción, L. (2005). Globalización, democracia y gobernanza global: perspectiva latinoamericana. Ponencia presentada en el VII Congreso Español de Ciencia Política y de la Administración. Democracia y buen gobierno, Madrid, España, 21 - 23 septiembre.

- Cunill, N. (1999). Retos de las reformas de segunda generación ¿Mercantilización y neoclientelismo o reconstrucción de la Administración Pública? Nueva Sociedad, 160. 
- Dussauge, M (2009). ¿Todos los caminos llevan a la nueva gestión pública? Tres argumentos sobre las reformas administrativas en los países en desarrollo/transición. Revista: Estado, Gobierno y Gestión Pública, № 13: pp. 23-51

- Echebarría, K. y Mendoza, X. (1999). La especificidad de la gestión pública: el concepto de management público. En C. Losada i Marrodán (Ed.), ¿De burócratas a gerentes? Las ciencias de la gestión aplicadas a la administración del Estado (pp. 11-46). Washington D.C.: BID.

- Ferrer, M. (2005). GGV: Hacer ciudad, legitimidad y gobernabilidad hacia una praxis ética de gobernación local en Venezuela. Revista: Espacio Abierto, 14(4), 631-660.

- Fleury, S. (2002). Reforma del Estado. Recuperado de http://www.top.org.ar/ecgp/FullText/000000/FLEURY\%20Soni a \%20-\%20Reforma\%20del\%20estado.pdf

- García, R. (2002). Choque Entre la Gobernabilidad Global y Local: Viejos Retos, Nuevas Expectativas. Recuperado de http://www.gobernabilidad.cl/modules.php?name=News\&file= article\&sid $=87$

- García, I. (2007). La nueva gestión pública: evolución y tendencias. Revista: Presupuesto y Gasto Público, 47, 37-64.

- Girvan, N. (s.f.). Problemas con los indicadores de gobernabilidad del PNUD. Recuperado de http://www.acsaec.org/columna/index45.htm

- GovernAsia. (2008). Cómo definimos la gobernanza y la gobernabilidad. Recuperado http://www.casaasia.es/governasia/blog/?cat=6

- Guerrero, O. (2000). El "Management" de la Interdependencia Global. Un Modelo de Gerencia Pública Estándar en la Era de la Globalización. Revista Digital Universitaria, 1(0). Recuperado de http://www.revista.unam.mx/vol.0/art1/modelo.html

(2001). Nuevos modelos de gestión pública. Revista

Digital Universitaria, 2(3). Recuperado de http://www.revista.unam.mx/vol.2/num3/art3/index.html

- . (2009). El fin de la nueva gerencia pública. Revista: Estado, Gobierno y Gestión Pública, № 13: pp. 5-22

- Herrera, R. (2005). ¿La buena gobernanza contra el buen gobierno? Revista Venezolana de Análisis de Coyuntura, Vol. X, No 1 (pp. 289 - 294). Universidad Central de Venezuela. Venezuela. Recuperado de http://www.gobernabilidad.cl/modules.php?name=News\&file= article \&sid $=804$

- Jarquín, E. y Losada i Marrodán, C. (1999). Aportes de las ciencias de gestión (management) a la reforma del estado. En C. Losada i Marrodán (Ed.), ¿De burócratas a gerentes? Las ciencias de la gestión aplicadas a la administración del Estado (pp. 1-7). Washington D.C.: BID.

- Lieberherr, F. (2002). ¿Por ciudades sostenibles? Urbanews, 6, 1.

- López, A. (2003). La Nueva Gestión Pública: algunas precisiones para su abordaje conceptual. Serie I: Desarrollo Institucional y Reforma del Estado. Documento $N^{\circ}$ 68. INAP.

- López, A. (Coord.). (2005). Indicadores de Gestión para el Monitoreo de las Políticas de Modernización en el Sector Público: revisión teórica y propuesta para su elaboración. Serie Desarrollo Institucional y Reforma del Estado, 71. 1a. ed. Buenos Aires. 
- Manteiga, L. (2000). Los indicadores ambientales como instrumento para el desarrollo de la política ambiental y su integración en otras políticas. Revista: Estadística y Medio Ambiente. Instituto de Estadística de Andalucía. Sevilla. España. (pp. 75-87).

- Metcalfe, L. (1999). La gestión pública: de la imitación a la innovación. En Carlos Losada i Marrodán (Ed.), ¿De burócratas a gerentes? Las ciencias de la gestión aplicadas a la administración del Estado (pp. 47-68). Washington D.C.: BID.

- OCDE. (1991). La administración al servicio del público. Madrid.

- Pliscoff, C. (2012). Dilemas teóricos post nueva gestión pública como parte de una revisión de la administración pública para América Latina: reflexiones a partir del eterno problema de la corrupción. Ponencia presentada en el XVII Congreso Internacional del CLAD sobre la Reforma del Estado y de la Administración Pública, Cartagena, Colombia, 30 oct. - 2 nov

- Prats, C. (2001). Gobernabilidad democrática para el desarrollo humano. Marco conceptual y analítico. Revista Instituciones y Desarrollo, 10, 103-148.

- Programa de las Naciones Unidas para el Desarrollo. (2000). Strategy Note on Governance for Human Development. Indicadores de gobernabilidad. Guía del usuario. 2da. Ed. New York: PNUD.

- Saldomando, Á. (2002). Medir la gobernabilidad ¿Quimera o instrumento de trabajo sobre qué? Recuperado de http://www.cinco.org.ni/archive/38.pdf

- Santos, J. (2008). Hacia una nueva gobernabilidad local en América Latina. Ponencia en XIII Congreso Internacional del CLAD sobre la Reforma del Estado y de la Administración Pública, Buenos Aires, Argentina, 4-7 noviembre.

- SELA. (1996). El "buen gobierno" y el fortalecimiento de la sociedad civil: Notas desde la Perspectiva de América Latina y el Caribe. Síntesis de los Debates. Anexo II: Consideraciones complementarias sobre los elementos constitutivos del "buen gobierno" desde la perspectiva de América Latina y el Caribe. Washington D.C.

- Shepherd, G. (1999). Administración pública en América Latina y el Caribe: en busca de un paradigma de reforma. En C. Losada i Marrodán (Ed.), ¿De burócratas a gerentes? Las ciencias de la gestión aplicadas a la administración del Estado (pp. 69-103). Washington D.C.: BID.

- Stiglitz, J. (2002). El Malestar en la Globalización. 1a. Ed. Santafé de Bogotá: Editorial Taurus.

- Suk, P. (2007). Desafíos a la capacidad publica en la era de una administración pública en evolución y reforma del gobierno. Gestión y Política Pública, XVI (2), 511-537.

- Teelken, C y van Gestel, N. (2004). Servicios de educación superior $y$ de seguridad social en los Países Bajos: Institucionalismo y nueva gestión política. Revista: Gestión y Política Pública. Vol. XIII. Nº02. Segundo semestre. Centro de Investigación y Docencia Económicas. México D.F.

- URB-AL. (2001). Documento Base Red 6 URB-AL sobre "Medio Ambiente Urbano". Málaga.

- Vargas, A. (2001). El estado y las políticas públicas. Almudena Editores. Bogotá. Colombia. 
- Vargas, J. (2005a). Hacia un nuevo diseño de gobernabilidad global postnacional. Polis, Revista Latinoamericana, 10. Recuperado de http://polis.revues.org/7553

- . (2005b). Transformación de la gobernabilidad económica global. Problemas del Desarrollo. Revista Latinoamericana de Economía, 36(142), 9-26.

1. Docente Investigadora, Universidad del Valle. diana.vasquez@correounivalle.edu.co

2. Docente Investigadora, Universidad del Valle. marcela.navarret@correounivalle.edu.co

3. Representante de Ciudades y Gobiernos Locales Unidos (CGLU) para América Latina.

4. Según Vargas (2005a), se refiere a "la cualidad de la sociedad que establece el conjunto de normas que estructuran las interrelaciones entre los diferentes actores estratégicos sociales y políticos y sus representantes, para regular los procesos de toma de decisiones así como los mecanismos para la resolución pacífica de conflictos".

5. Existe una suposición implícita de que los sistemas políticos multipartidistas del Occidente son el ideal según el cual deben medirse todos los países. Por ende, la mayoría de los países de la OCDE obtienen una puntuación perfecta en los indicadores de Política, Libertades Civiles y Derechos Políticos.

6. Para García (2007), la gobernabilidad democrática debe ser entendida como una cualidad de la sociedad que establece el conjunto de normas que estructuran las interrelaciones entre los diferentes actores estratégicos sociales y políticos y sus representantes, para regular los procesos de toma de decisiones. Así como los mecanismos para la resolución pacífica de conflictos.

Para citar este artículo: Vásquez-Avellaneda, D.M., NavarretePeñuela, M. (2014). La gobernabilidad local en el contexto de la nueva gestión pública: requisito para la gestión ambiental urbana.

Revista Luna Azul, 39, 63-88. Recuperado de http://lunazul.ucaldas.edu.co/index.php?option=content\&tas $\mathrm{k}=\mathrm{view} \& \mathrm{id}=948$ 